\title{
Impaired Social and Role Function in Ultra-High Risk for Psychosis and First-Episode Schizophrenia: Its Relations with Negative Symptoms
}

\author{
So Jung Lee ${ }^{1}$, Kyung Ran Kim, ${ }^{1,2}$ Su Young Lee ${ }^{2,3}$, and Suk Kyoon $\mathrm{An}^{1,2,4 凶}$ \\ ${ }^{1}$ Department of Psychiatry, Yonsei University College of Medicine, Severance Hospital, Yonsei University Health System, Seoul, Republic of Korea \\ ${ }^{2}$ Section of Self, Affect and Neuroscience, Institute of Behavioral Science in Medicine, Yonsei University College of Medicine, Seoul, Republic of Korea \\ ${ }^{3}$ Department of Psychiatry, Cheil General Hospital \& Women's Healthcare Center, Dankook University College of Medicine, Seoul, \\ Republic of Korea \\ ${ }^{4}$ Graduate Program in Cognitive Science, Yonsei University, Seoul, Republic of Korea
}

Objective Psychosocial dysfunction was a nettlesome of schizophrenia even in their prodromal phase as well as first episode and its relations with psychopathology were not determined. The aim of the present study was to examine whether the social and role function impairment was found in ultra-high risk for psychosis (UHR) individuals as well as first-episode schizophrenia patients and to explore its relations with psychopathology.

Methods Thirty-seven normal controls, 63 UHR participants and 28 young, first-episode schizophrenia patients were recruited. Psychosocial functioning was examined by using Global function: Social and Role scale. Psychopathologies of positive, negative and depressive symptom were also measured.

Results Social and role functioning in UHR were compromised at the equivalent level of those of first-episode schizophrenia patients Multiple linear regression analysis revealed that social and role dysfunction was associated with negative symptoms in each UHR and first-episode schizophrenia group.

Conclusion These findings suggest that the significant impairment of social and role function may be appeared before the active psychosis onset at the level of extent to those of first-episode schizophrenia patients. The psychosocial intervention strategy especially targeting the negative symptoms should be developed and provided to individuals from their prepsychotic stage of schizophrenia.

Psychiatry Investig 2017;14(2):186-192

Key Words Schizophrenia, First episode, Ultra-high risk, Social dysfunction, Role dysfunction.

\section{INTRODUCTION}

Schizophrenia is a disorder with impaired functioning for a significant portion of the time since the onset of the disturbance. ${ }^{1}$ Impairment in one or more major areas of functioning, such as work or interpersonal relations can be found not only in chronic, multi-episodes schizophrenia patients but also in first-episode patients and even in individuals at ultra-high

Received: May 31, 2016 Revised: August 1, 2016

Accepted: August 3, 2016 Available online: October 13, 2016

$\triangle$ Correspondence: Suk Kyoon An, MD, PhD

Department of Psychiatry, Yonsei University College of Medicine, Severance Hospital, Yonsei University Health System, 50-1 Yonsei-ro, Seodaemun-gu, Seoul 03722, Republic of Korea

Tel: +82-2-2228-1585, Fax: +82-2-313-0891, E-mail: ansk@yuhs.ac

(a) This is an Open Access article distributed under the terms of the Creative Commons Attribution Non-Commercial License (http://creativecommons.org/licenses/bync/4.0) which permits unrestricted non-commercial use, distribution, and reproduction in any medium, provided the original work is properly cited. risk (UHR) for psychosis. ${ }^{2,3}$ In UHR individuals, baseline low functional level or declining of functional level during few years of follow-up was reported to be significant predictor of transition into overt psychotic disorder. ${ }^{4}$ The psychosocial dysfunction in first-episode patients ${ }^{5,6}$ was generally reported to be associated with negative symptoms rather than positive symptoms. These findings indicate that functional decline may be not chronic illness-related factor or effect of drugs such as antipsychotics rather trait of the disease itself, which can be derived from the lesions of the neurodevelopmental origin.?

There were some different pictures of psychosocial dysfunction depending on the phase of illness and domains of functioning. The social function in UHR was shown to be significantly compromised, and the extent of impairment was comparable to that of first-episode and multi-episode schizophrenia patients. Meanwhile, role function in UHR was significantly 
declined to that of first-episode patients but better than that of multi-episode patients. ${ }^{8}$ Furthermore, it was reported that role functioning did not predict later psychosis transition independently of social functioning in UHR. ${ }^{9}$

In schizophrenia, there were heterogeneous findings on the relationship of psychosocial disability with psychopathologies including negative symptoms ${ }^{10-19}$ and depressive symptoms. ${ }^{13,16,20}$ These mixed findings may be resulted from the clinical status of schizophrenia (first episode ${ }^{15,19}$ vs. multi-episode or mixed), ${ }^{10-14,16-18,20}$ psychosocial function measurement tools [objective measures $^{10,11,13-15,17-20}$ vs. subjective measures $\left.{ }^{11-13,16}\right]$ and other factors. In UHR, most studies found that the psychosocial impairment was associated with negative symptoms ${ }^{21-25}$ while few reports showed the relations with depressive symptoms. ${ }^{25-27}$ Overall, the previous studies suggest that the negative symptoms rather than depressive and positive one showed strong association with objectively-assessed psychosocial disability in UHR and early-stage schizophrenia patients. Therefore, greater knowledge concerning the social and role functioning and its relations with prodromal psychopathologies would provide the clues for the development of the indicated prevention and early intervention strategies in these help-seeking clinical groups.

The aim of the study was to examine whether the social and role function impairment was found in UHR individuals as well as first-episode schizophrenia patients and to explore its relations with psychopathology. Based on the previous studies, our hypothesis was that both clinical groups showed social and role functioning deficits and the extent of these deficits in both groups may be comparable. In addition, we also expected that social and role disability may be associated with negative symptoms rather than positive and depressive symptoms. For explorative purpose, we observed the relations of social and role dysfunction with two major negative items of affective flattening and avolition, which have not yet been studied extensively in these clinical groups.

\section{METHODS}

\section{Participants}

The participants were consisted of normal controls (NC), individuals at UHR for psychosis, and first-episode schizophrenia patients. $37 \mathrm{NC}$ were recruited from internet advertisements. The 63 UHR participants were from the "Clinic FORYOU" at Severance Hospital of Yonsei University Health System between July 2007 and June 2009. The Clinic FORYOU was established in March 2007 as an UHR research clinic of the "GRAPE" (Green Program for Recognition and Prevention of Early Psychosis) project. The 28 young first-episode patients with schizophrenia enrolled in our study were re- cruited from both the outpatient (15) and inpatient (13) service units of Severance Hospital and Severance Mental Health Hospital of Yonsei University Health System during the same time period. All patients with schizophrenia were in clinically stable or stabilization phase. All participants met the inclusion criteria of being between 15-35 years old and having more than nine years of education. Participants were evaluated by using the Structured Clinical Interview for the Diagnostic and Statistical Manual of Mental Disorders (DSM-IV). ${ }^{28,29}$ The exclusion criteria were current or past history of neurological illness or traumatic brain injury; current or past psychiatric illness history for the NC; and current or past diagnosis of major psychiatric disorder with psychotic features for UHR patients.

The UHR participants were diagnosed by the Criteria of the Prodromal Syndromes of SIPS. ${ }^{30}$ The DSM-IV diagnoses of the UHR participants were as follows: any mood disorder, including any depressive $(n=23)$ /bipolar disorder $(n=1)$; any anxiety disorder $(n=14)$, including social phobia $(n=9)$; any eating disorder $(n=1)$; other axis I disorder $(n=2)$ and schizotypal personality disorder $(n=5)$. The diagnosis of schizophrenia was made according to the criteria of the DSM-IV using the SCID. ${ }^{29}$ This study was carried out in accordance with the Declaration of Helsinki. The Institutional Review Boards at Severance Hospital and Severance Mental Health Hospital reviewed and approved this study. All participants were given written informed consent. Written informed consent was obtained from all subjects and additionally from the parents if subjects were under 18 years of age.

\section{Measures}

\section{Global functioning: Social (GF: Social) and Global functioning: Role (GF: Role)}

In this article, we used the Global functioning: Social (GF: Social $)^{31}$ and Global functioning: Role (GF: Role) ${ }^{32}$ to assess the psychosocial functioning in the participants. Score of the both scales range from 1 to 10 , with 10 indicating superior functioning and 1 indicating extreme dysfunction. To increase reliability, both scales include focused and detailed anchor points for each rating interval. Experienced clinicians summarized other previously collected data and directed interview guided by the accompanying probes. Each scale generates 3 scores: current functioning which is the lowest level of functioning in the past month, lowest and highest level of functioning reported over the past year. In the present study, we used the present level of functioning.

The GF: Social scale rated quantity and quality of age appropriate intimate relationships, peer relationships, level of peer conflict, and involvement with family members. Interac- 
tions with people other than family members got higher score than interactions limited only to family members. Etiology of social dysfunction or levels of clinical symptomatology were not considered when rating the scale. The GF: Role scale emphasized the level of support provided within the individual's environment and the individual's performance given such support in addition to age appropriateness. The ratings were based on performance in school, work, or home.

\section{Other psychosocial measures}

To assess psychopathologies and symptom severities, the scale for the assessment of positive symptoms (SAPS), ${ }^{33}$ the scale for the assessment of negative symptoms (SANS), ${ }^{34}$ the Montgomery-Asberg Depression Rating Scale (MADRS) ${ }^{35}$ were used. The sum of summary scores of 4 items of SAPS and 5 items of SANS were used. In addition, the summary scores of affective flattening or blunting and avolition-apathy were used for further exploration, since these 2 items were proposed to be particularly prominent in schizophrenia. ${ }^{1}$

\section{Procedure}

Clinical interviews and assessments were administered by a psychiatrist within a week after recruitment into the study.

\section{Statistical analysis}

To compare the GF: Social and GF: Role between the three groups, multivariate analyses of variance (ANOVA) were used. Post-hoc analysis was done also with Bonferroni correc- tion. Pearson correlations of two GF scales with psychopathologies were conducted by using the SANS, SAPS, MADRS in each clinical group. All variables significantly correlated with GF: Social and GF: Role scores were analyzed subsequently using a multiple linear regression to evaluate their independent and primary contributions to each GF: Social and GF: Role scores. Stepwise method was utilized in the regression model, and pairwise deletion was utilized for missing data. For exploration of association with specific negative symptom items such as affective flattening or blunting and avolition-apathy, the same statistical analysis was also conducted. A significance level of $\mathrm{p}$ less than 0.05 was used for all tests.

\section{RESULTS}

\section{Demographic and clinical profiles of the participants}

There was no difference between the three groups in age, total durations of education, or distribution of sex (Table 1). The UHR patients and first-episode schizophrenia patients both showed more positive, negative and depressive symptoms than normal controls. First-episode schizophrenia patients showed more positive and less depressive symptoms than UHR patients. The difference of negative symptoms between UHR patients and first-episode schizophrenia did not reach a significant level.

Table 1. Demographic and clinical profiles of normal controls, ultra-high risk (UHR) for psychosis, and first-episode schizophrenia patients

\begin{tabular}{|c|c|c|c|}
\hline & $\begin{array}{l}\text { Normal controls } \\
\qquad(\mathrm{N}=37)\end{array}$ & $\begin{array}{l}\text { UHR for psychosis } \\
\qquad(\mathrm{N}=63)\end{array}$ & $\begin{array}{l}\text { First-episode schizophrenics } \\
\qquad(\mathrm{N}=28)\end{array}$ \\
\hline Age (years) & $20.6(3.1)$ & $19.7(3.5)$ & $20.6(2.7)$ \\
\hline Education (years) & $13.2(1.7)$ & $12.6(1.8)$ & $12.8(1.9)$ \\
\hline $\operatorname{Sex}(M / F)$ & $17 / 20$ & $38 / 25$ & $13 / 15$ \\
\hline SIPS-defined prodromal status (BIPS/APS/GRDS) & & $10 / 57 / 8$ & \\
\hline Type (paranoid/undifferentiated/residual) & & & $23 / 3 / 2$ \\
\hline Positive symptoms of SAPS*tł & $0.0(0.0)$ & $3.2(2.2)$ & $6.4(2.8)$ \\
\hline Negative symptoms of SANS*† & $0.5(0.2)$ & $7.9(4.3)$ & $8.8(4.8)$ \\
\hline Depressive symptoms of MADRS*+‡ & $1.3(3.2)$ & $21.2(10.1)$ & $15.7(10.4)$ \\
\hline \multicolumn{4}{|l|}{ Antipsychotic medications } \\
\hline Naïve/medicated $\ddagger$ & & $38 / 25$ & $1 / 27$ \\
\hline Chlorpromazine equivalent dose $(\mathrm{mg} / \mathrm{d})^{\ddagger}$ & & $135.3(103.3)$ & $445.7(324.6)$ \\
\hline
\end{tabular}

*significant difference between normal controls and UHR patients for psychosis $(\mathrm{p}<0.05),{ }^{\dagger}$ significant difference between normal controls and first-episode schizophrenia patients $(\mathrm{p}<0.05)$, „significant difference between UHR for psychosis and first-episode schizophrenia patients $(\mathrm{p}<0.05)$. SAPS (Andreason, 1983): Scale for Assessment of Positive Symptoms, 2 UHR data are missing, SANS (Andreason, 1983): Scale for Assessment of Negative Symptoms, 2 UHR data are missing, SIPS (McGlashan et al., 2003): Structured Interview for Prodromal Syndromes; MADRS (Montgomery and Asberg, 1979): Montgomery-Åsberg Depression Rating Scale, 4 First-episode schizophrenics data are missing. BIPS: Brief Intermittent Psychotic Symptom Prodromal Syndrome, APS: Attenuated Positive Symptom Prodromal Syndrome, GRDS: Genetic Risk and Deterioration Prodromal Syndrome 


\section{Comparisons of Global functioning: Social} (GF: Social) and Global functioning: Role (GF: Role) between UHR, first-episode schizophrenia and normal control groups

The GF: Social and GF: Role in normal controls, ultra-high risk (UHR) patients for psychosis, and first-episode schizophrenia patients are shown in Table 2. Multivariate ANOVA revealed a significant difference between the groups overall $[F(4,250)=29.4, p<0.001]$. A follow-up series of univariate ANOVA showed significant differences for the GF: Social [F $(2,125)=104.7, \mathrm{p}<0.001]$ and GF: Role $[\mathrm{F}(2,125)=49.0, \mathrm{p}<$ $0.001]$. As shown in Table 2, post hoc testing using the Bonferroni correction showed that UHR participants and firstepisode patients exhibited a significantly impaired GF: Social than NC did (vs. UHR $\mathrm{p}<0.001$, vs. FE $\mathrm{p}<0.001$ ). Also, UHR participants and first-episode patients showed significantly impaired GF: Role than NC did (vs. UHR p $<0.001$, vs. FE $\mathrm{p}<0.001)$. UHR participants did not differ significantly from the first-episode patients $(\mathrm{p}>0.999)$ for GF: Social or GF: Role.

\section{Preliminary correlations of Global functioning: Social (GF: Social) and Global functioning: Role (GF: Role) with psychopathology in individuals at ultra-high risk (UHR) for psychosis, and first-episode schizophrenia patients}

Pearson's correlation analysis revealed that in UHR patients (Table 3), GF: Social and GF: Role were significantly correlated with negative symptoms of SANS $(r=-0.60, p<0.001$; $\mathrm{r}=-0.42, \mathrm{p}=0.001$, in respect) and depressive symptoms of MADRS ( $\mathrm{r}=-0.55, \mathrm{p}=0.003 ; \mathrm{r}=-0.40, \mathrm{p}=0.001$, respectively). In addition, GF: Social was significantly correlated with affective flattening or blunting item and avolition-apathy item of SANS ( $\mathrm{r}=-0.37, \mathrm{p}<0.001 ; \mathrm{r}=-0.51, \mathrm{p}<0.001$, in respect) and GF: Role was significantly correlated with avolition-apathy item of SANS ( $\mathrm{r}=-0.40, \mathrm{p}=0.002)$.

In first-episode schizophrenia patients (Table 3), the Pearson's correlation analyses showed that GF: Social were correlated with negative symptoms of SANS ( $\mathrm{r}=-0.49, \mathrm{p}=0.008$ ) and depressive symptoms of MADRS $(\mathrm{r}=-0.46, \mathrm{p}=0.024)$ and GF: Role was correlated with negative symptoms of SANS $\mathrm{r}=-0.46, \mathrm{p}=0.014)$. In addition, GF: Social was significantly correlated with avolition-apathy item of SANS ( $r=-0.47$, $\mathrm{p}=0.011)$ and GF: Role was significantly correlated with avolition-apathy item of SANS $(\mathrm{r}=-0.44, \mathrm{p}=0.020)$. There were

Table 2. Global functioning: Social (GF: Social) and Global functioning: Role (GF: Role) in normal controls, ultra-high risk (UHR) individuals for psychosis, and first-episode schizophrenia patients

\begin{tabular}{|c|c|c|c|c|c|c|}
\hline & $\begin{array}{l}\text { Normal controls } \\
\qquad(\mathrm{N}=37)\end{array}$ & $\begin{array}{l}\text { UHR patients for } \\
\text { psychosis }(\mathrm{N}=63)\end{array}$ & $\begin{array}{c}\text { First-episode } \\
\text { schizophrenia } \\
\text { patients }(\mathrm{N}=28)\end{array}$ & $\begin{array}{c}\text { F-values, d.f. } \\
\text { p-values }\end{array}$ & Post-hoc & $\begin{array}{l}\text { Corrected } \\
\text { p-values }\end{array}$ \\
\hline \multirow[t]{3}{*}{ GF: social } & $8.6(0.7)$ & $4.8(1.6)$ & $4.9(1.4)$ & $\mathrm{F}(2,125)=104.7$ & N vs. U & $<0.001$ \\
\hline & & & & $\mathrm{p}<0.001$ & N vs. S & $<0.001$ \\
\hline & & & & & U vs. S & $>0.999$ \\
\hline \multirow[t]{3}{*}{ GF: role } & $8.1(0.9)$ & $5.2(1.7)$ & $5.0(1.7)$ & $\mathrm{F}(2,125)=49.0$ & N vs. U & $<0.001$ \\
\hline & & & & $\mathrm{p}<0.001$ & N vs. S & $<0.001$ \\
\hline & & & & & U vs. S & $>0.999$ \\
\hline
\end{tabular}

Corrected $\mathrm{p}=$ uncorrected $\mathrm{p} \times 3$

Table 3. Correlations of Global functioning: Social (GF: Social) and Global functioning: Role (GF: Role) with psychopathology in ultra-high risk (UHR) individuals for psychosis, and first-episode schizophrenia patients

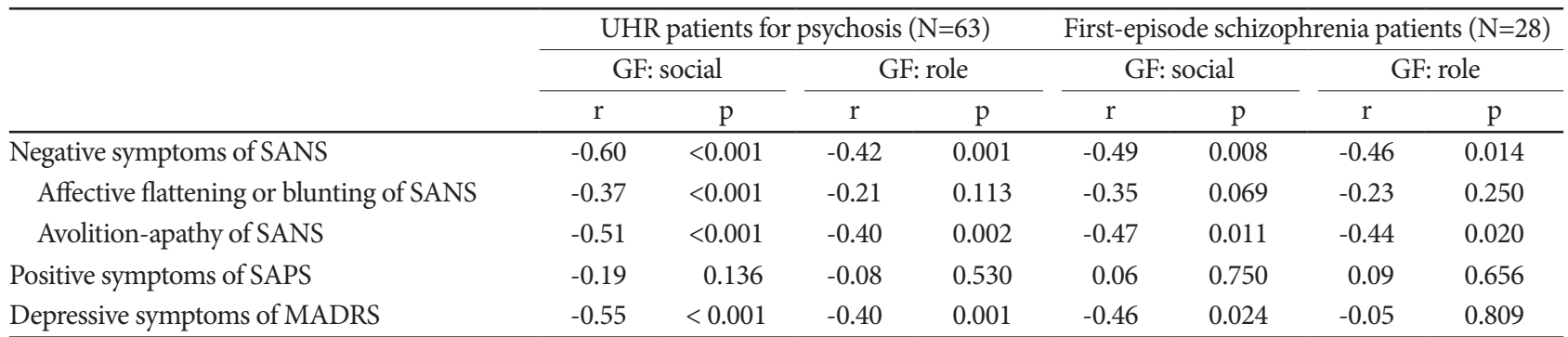

SAPS (Andreason, 1983): Scale for Assessment of Positive Symptoms; 2 UHR data are missing; SANS (Andreason, 1983): Scale for Assessment of Negative Symptoms; 2 UHR data are missing; MADRS (Montgomery and Asberg, 1979): Montgomery-Åsberg Depression Rating Scale; 4 First-episode schizophrenics data are missing 
no other significant correlations.

\section{Multiple linear regression analysis of Global functioning: Social (GF: Social) and Global functioning: Role (GF: Role) with other variables}

In UHR, overall full regression model was significant and the negative symptoms accounted for $35 \%$ of the variance in social dysfunction $(\beta=-0.60, t=-5.76, p<0.001)$ and for $17 \%$ of the variance in role dysfunction $(\beta=-0.42, t=-3.60, p=0.001)$. The positive symptoms (for social dysfunction: $\beta=-0.08, t=-0.77$, $\mathrm{p}=0.445$; for role dysfunction: $\beta=-0.01, \mathrm{t}=-0.10, \mathrm{p}=0.992)$ and depressive symptoms (for social dysfunction: $\beta=-0.26, t=-1.87$, $\mathrm{p}=0.066$; for role dysfunction: $\beta=-0.20, \mathrm{t}=-1.22, \mathrm{p}=0.227$ ) were excluded. For specific negative items, overall full regression model was significant and the avolition-apathy item accounted for $26 \%$ of the variance in social dysfunction $(\beta=-0.51, t=-4.55$, $\mathrm{p}<0.001)$ and for $16 \%$ of the variance in role dysfunction $(\beta=-0.51$, $\mathrm{t}=-4.55, \mathrm{p}<0.001$ ). The affective flattening or blunting item (for social dysfunction: $\beta=-0.13, t=-0.96, p=0.343$; for role dysfunction: $\beta=0.18, t=0.13, p=0.900)$ was excluded.

In first-episode schizophrenia patients, the negative symptoms accounted for $21 \%$ of the variance in social dysfunction $(\beta=-0.49, t=-2.66, p=0.014)$ and for $17 \%$ of the variance in role dysfunction $(\beta=-0.46, \mathrm{t}=-2.41, \mathrm{p}=0.025)$. The positive symptoms (for social dysfunction: $\beta=0.04, \mathrm{t}=0.21, \mathrm{p}=0.839$; for role dysfunction: $\beta=0.07, t=-0.34, p=0.737$ ) and depressive symptoms (for social dysfunction: $\beta=-0.31, t=-1.59, \mathrm{p}=0.127$; for role dysfunction: $\beta=0.16, t=0.75, p=0.460)$ were excluded. For specific negative items, overall full regression model was significant and the avolition-apathy item accounted for $19 \%$ of the variance in social dysfunction $(\beta=-0.47, t=-2.74, p=0.011)$ and for $19 \%$ of the variance in role dysfunction $(\beta=-0.44, t=-2.48$, $\mathrm{p}=0.020$ ). The affective flattening or blunting item (for social dysfunction: $\beta=-0.05, t=-0.20, p=0.840$; for role dysfunction: $\beta=0.14, t=0.56, p=0.580$ ) was excluded. The tolerance among the predictors did not indicate multi-collinearity (all VIF $<1.1$ ). A summary of regression analysis was shown in Table 4 and 5.

\section{DISCUSSION}

The aim of the present study was first, to examine whether UHR individuals as well as first-episode schizophrenia patients would show significantly impaired social and role function, and second was to explore the relations between each function and psychopathologies such as positive, negative, and depressive symptoms. Our main findings were that UHR participants and first-episode patients exhibited a significantly impaired social and role functioning than normal controls did. Meanwhile, decline of the social and role functioning in UHR were not different from those of first-episode schizophrenia patients, which matched with our hypothesis. Social and role function impairment were primarily and independently associated with negative symptoms but not associated with depressive nor positive symptom in each UHR and first-episode schizophrenia group.

UHR participants as well as first-episode schizophrenia patients showed marked impairment in social and role function than normal control group. More importantly, the extent

Table 4. Multiple linear regression analysis of Global functioning: Social (GF: Social) and Global functioning: Role (GF: Role) with psychopathologies in each clinical group

\begin{tabular}{lllrrrrrrrr}
\hline & & \multirow{2}{*}{ Determinants } & \multicolumn{5}{c}{ Participants } \\
\cline { 5 - 10 } & & & $\beta^{*}$ & $\mathrm{t}$ & $\mathrm{P}$ & $\Delta \mathrm{R}^{2 \dagger}$ & $\mathrm{R}^{2 \ddagger}$ & $\mathrm{F}$ & $\mathrm{df}$ & $\mathrm{p}$ \\
\hline UHR (N=63) & GF: social & Negative symptom & -0.60 & -5.76 & $<0.001$ & 0.36 & 0.35 & 33.2 & 1,59 & $<0.001$ \\
& GF: role & Negative symptom & -0.42 & -3.60 & 0.001 & 0.18 & 0.17 & 13.0 & 1,59 & 0.001 \\
First-episode schizophrenia & GF: social & Negative symptom & -0.49 & -2.66 & 0.014 & 0.24 & 0.21 & 7.1 & 1,22 & 0.014 \\
patients (N=28) & GF: role & Negative symptom & -0.46 & -2.41 & 0.025 & 0.21 & 0.17 & 5.8 & 1,22 & 0.025 \\
\hline
\end{tabular}

All VIF $<1.1$. *standardized coefficient, ${ }^{\dagger}$ changed variance, $\Delta \mathrm{R}^{2}$, ${ }^{\ddagger}$ adjusted $\mathrm{R}^{2}$, explained variance by model. UHR: ultra-high risk

Table 5. Multiple linear regression analysis of Global functioning: Social (GF: Social) and Global functioning: Role (GF: Role) with specific negative item in each clinical group

\begin{tabular}{|c|c|c|c|c|c|c|c|c|c|c|}
\hline & & \multirow{2}{*}{ Determinants } & \multicolumn{8}{|c|}{ Participants } \\
\hline & & & $\beta^{*}$ & $\mathrm{t}$ & $\mathrm{P}$ & $\Delta \mathrm{R}^{2 \dagger}$ & $\mathrm{R}^{2 \ddagger}$ & $\mathrm{F}$ & $\mathrm{df}$ & $\mathrm{p}$ \\
\hline \multirow[t]{2}{*}{ UHR (N=63) } & GF: social & Avolition-apathy item & -0.60 & -5.76 & $<0.001$ & 0.26 & 0.25 & 20.7 & 1,59 & $<0.001$ \\
\hline & GF: role & Avolition-apathy item & -0.42 & -3.66 & 0.001 & 0.16 & 0.14 & 10.9 & 1,59 & 0.002 \\
\hline \multirow{2}{*}{$\begin{array}{l}\text { First-episode schizophrenia } \\
\text { patients }(\mathrm{N}=28)\end{array}$} & GF: social & Avolition-apathy item & -0.49 & -2.66 & 0.014 & 0.22 & 0.19 & 7.5 & 1,26 & 0.011 \\
\hline & GF: role & Avolition-apathy item & -0.46 & -2.41 & 0.025 & 0.19 & 0.16 & 6.2 & 1,26 & 0.020 \\
\hline
\end{tabular}

All VIF $<1.1 .{ }^{*}$ standardized coefficient, ${ }^{\dagger}$ changed variance, $\Delta \mathrm{R}^{2}$, ${ }_{\text {adjusted }}{ }^{2}$, explained variance by model. UHR: ultra-high risk 
of impairment in UHR group was comparable to that of firstepisode schizophrenia patients. These findings were compatible to those of previous studies. ${ }^{2,3,8,17}$ It was suggested that the impairment in social and role functioning are already emerged from the putative prodromal phase at the equivalent level of first-episode schizophrenia patients, which is compatible to the neurodevelopmental model of schizophrenia. ${ }^{36}$

Psychosocial functional deficits for social and role domains were primarily associated with negative symptoms of SANS but not associated with depressive nor positive symptoms in each clinical group. At first, depressive symptoms and psychosocial functioning seemed to have association with simple correlation, but it turned out to be not primarily related when we did the regression analysis. These findings were generally compatible to those of previous studies in first-episode schizophrenia $^{15,19}$ and UHR individuals. ${ }^{21-24}$ There were a few reports of correlations of psychosocial dysfunction with depressive symptoms in first-episode schizophrniea patients ${ }^{13,16,20}$ and UHR individuals. ${ }^{25-27}$ However, this correlations with depressive symptoms were only found when the assessment of psychosocial dysfunction was done by using subjective selfrate measurement, ${ }^{13,16,20,25,26}$ except one. ${ }^{27}$ Generally, the self reported complaints of depression was not reported to be highly correlated with objective measure of depression at least partly due to the confounding effects of the personality characteristics of subjects, ${ }^{36}$ which can be also a major associated factors of psychosocial functioning. Thus, the different findings may be possible according to the measurements tools of the self-reported and objectively rated severity of depression, though the exact reason of these findings is uncertain. It is also noteworthy that the depressive symptoms should not be neglected, since this psychopathology may be an another enhancing risk for transition of overt psychosis. ${ }^{37}$ The finding that the positive symptoms do not appear to be a major independent factor of psychosocial functional disability is compatible to the lack of effectiveness of current pharmacotherapy for the psychosocial disability in schizophrenia group. The extents of relationship between negative symptoms and social and role dysfunction in each clinical group were within the level of the moderate size (18-35\%). Thus, to improve the social and role dysfunction, the psychosocial intervention strategy should address the negative symptoms.

The limitations of our study should be noticed. First, the first-episode groups were in clinically stabilized state. Thus, our findings of association of functioning with the negative symptom not with the positive one cannot be generalized into the whole schizophrenia patients populations regardless of their psychotic symptoms status. Second, there was no followup data to elucidate the causal relations of psychosocial functional impairment and psychopathologies. Long-term follow- up studies are needed to be our understanding of the important contributions of psychopathology to social and role dysfunction in UHR and first-episode schizophrenia patients. Lastly, the other variables such as neurocognitive and social cognitive function are not assessed. These factors may be differentially interacted with negative symptoms for developing impairment of social and role functioning in these clinical groups. For long-term follow-up studies, all these factors should be promote our understanding of the whole pictures of psychosocial dysfunction in schizophrenia from their early prepsychotic stage.

In conclusions, our study found that UHR participants showed significantly impaired social and role functioning at the level of the first-episode schizophrenia patients. In addition, in each stabilized clinical group, social and role dysfunction were primarily and independently associated with negative symptoms but not with depressive and positive symptoms. These findings implicate that the significant impairment of social and role function may be appeared before the active psychosis onset in schizophrenia and thus the psychosocial intervention especially targeting the negative symptoms should be actively provided in their prepsychotic stage and in their stabilized states of schizophrenia. In near future, it is needed to be examined whether the improving the negative symptoms or psychosocial functioning would be play an important role for preventing the transition of UHR states into overt psychotic disorder.

\section{Acknowledgments}

We thank the Korea Health Technology R\&D Project through the Korea Health Industry Development Institute (KHIDI), funded by the Ministry of Health \& Welfare, Republic of Korea (grant number: HI14C2242).

\section{REFERENCES}

1. American Psychiatric Association. DSM-5: Diagnostic and Statistical Manual of Mental Disorders, 5th Edition. Washington, DC: American Psychiatric Publishing; 2013.

2. Yung AR, Phillips LJ, Yuen HP, Francey SM, McFarlane CA, Hallgren $\mathrm{M}$, et al. Psychosis prediction: 12-month follow up of a high-risk ("prodromal") group. Schizophr Res 2003;60:21-32.

3. Yung AR, Phillips LJ, Yuen HP, McGorry PD. Risk factors for psychosis in an ultra high-risk group: Psychopathology and clinical features. Schizophr Res 2004;67:131-142.

4. Velthorst E, Nelson B, Wiltink S, de Haan L, Wood SJ, Lin A, et al. Transition to first episode psychosis in ultra high risk populations: does baseline functioning hold the key?. Schizophr Res 2013;143:132137.

5. Valmaggia LR, Stahl D, Yung AR, Nelson B, Fusar-Poli P, McGorry $\mathrm{PD}$, et al. Negative psychotic symptoms and impaired role functioning predict transition outcomes in the at-risk mental state: a latent class cluster analysis study. Psychol Med 2013;43:2311-2325.

6. Addington J, van Mastrigt S, Addington D. Patterns of premorbid functioning in first-episode psychosis: initial presentation. Schizophr Res 2003;62:23-30.

7. Rapoport JL, Addington AM, Frangou S, Psych MR. The neurodevelopmental model of schizophrenia: update 2005. Mol Psychiatry 2005;10: 434-449. 
8. Addington J, Penn D, Woods SW, Addington D, Perkins DO. Social functioning in individuals at clinical high-risk for psychosis. Schizophr Res 2008;99:119-124.

9. Cannon TD, Cadenhead K, Cornblatt B, Woods SW, Addington J, Walker E, et al. Prediction of psychosis in youth at high clinical risk: a multisite longitudinal study in North America. Arch Gen Psychiatry 2008;65:28-37.

10. Perlick DA, Rosenheck RA, Kaczynski R, Bingham S, Collins J. Association of symptomatology and cognitive deficits to functional capacity in schizophrenia. Schizophr Res 2008;99:192-199.

11. Yamauchi K, Aki H, Tomotake M, Iga J, Numata S, Motoki I, et al. Predictors of subjective and objective quality of life in outpatients with schizophrenia. Psychiatry Clin Neurosci 2008;62:404-411.

12. Woon PS, Chia MY, Chan WY, Sim K. Neurocognitive, clinical and functional correlates of subjective quality of life in Asian outpatients with schizophrenia. Prog Neuropsychopharmacol Biol Psychiatry 2010;34:463-468.

13. Narvaez JM, Twamley EW, McKibbin CL, Heaton RK, Patterson TL. Subjective and objective quality of life in schizophrenia. Schizophr Res 2008;98:201-208.

14. Mohamed S, Rosenheck R, Swartz M, Stroup S, Lieberman JA, Keefe RS. Relationship of cognition and psychopathology to functional impairment in schizophrenia. Am J Psychiatry 2008;165:978-987.

15. Stouten LH, Veling W, Laan W, van der Helm M, van der Gaag M. Psychotic symptoms, cognition and affect as predictors of psychosocial problems and functional change in first-episode psychosis. Schizophr Res 2014;158:113-119.

16. Strauss GP, Sandt AR, Catalano LT, Allen DN. Negative symptoms and depression predict lower psychological well-being in individuals with schizophrenia. Compr Psychiatry 2012;53:1137-1144.

17. Rabinowitz J, Levine SZ, Garibaldi G, Bugarski-Kirola D, Berardo CG, Kapur S. Negative symptoms have greater impact on functioning than positive symptoms in schizophrenia: analysis of CATIE data. Schizophr Res 2012;137:147-150.

18. Hunter R, Barry S. Negative symptoms and psychosocial functioning in schizophrenia: neglected but important targets for treatment. Eur Psychiatry 2012;27:432-436.

19. Song YY, Kim KR, Park JY, Lee SY, Kang JI, Lee E, et al. Associated factors of quality of life in first-episode schizophrenia patients. Psychiatry Investig 2011;8:201-206.

20. Rocca P, Bellino S, Calvarese P, Marchiaro L, Patria L, Rasetti R. et al. Depressive and negative symptoms in schizophrenia: different effects on clinical features. Compr Psychiatry 2005;46:304-310.

21. Masillo A, Valmaggia LR, Saba R, Brandizzi M, Lindau JF, Solfanelli A, et al. Interpersonal sensitivity and functioning impairment in youth at ultra-high risk for psychosis. Eur Child Adolesc Psychiatry 2016;25:716.

22. Svirskis T, Korkeila J, Heinimaa M, Huttunen J, Ilonen T, Ristkari T, et al. Quality of life and functioning ability in subjects vulnerable to psy- chosis. Compr Psychiatry 2007;48:155-160.

23. Schlosser DA, Campellone TR, Biagianti B, Delucchi KL, Gard DE, Fulford D, et al. Modeling the role of negative symptoms in determining social functioning in individuals at clinical high risk of psychosis. Schizophr Res 2015;169:204-208.

24. Kim KR, Song YY, Park JY, Lee EH, Lee M, Lee SY, et al. The relationship between psychosocial functioning and resilience and negative symptoms in individuals at ultra-high risk for psychosis. Aust N Z J Psychiatry 2013;47:762-771.

25. Corcoran CM, Kimhy D, Parrilla-Escobar MA, Cressman VL, Stanford AD, Thompson J, et al. The relationship of social function to depressive and negative symptoms in individuals at clinical high risk for psychosis. Psychol Med 2011;41:251-261.

26. Ruhrmann S, Paruch J, Bechdolf A, Pukrop R, Wagner M, Berning J, et al. Reduced subjective quality of life in persons at risk for psychosis. Acta Psychiatr Scand 2008;117:357-368.

27. Olvet DM, Carrión RE, Auther AM, Cornblatt BA. Self-awareness of functional impairment in individuals at clinical high-risk for psychosis. Early Interv Psychiatry 2015;9:100-107.

28. First MB, Gibbon M, Spitzer RL, Williams JB. Structured Clinical Interview for DSM-IV Axis I Disorders: Non-Patients Edition (SCID-I/ NP). New York: Biometrics Research, New York State Psychiatric Institute; 2002.

29. First MB, Gibbon M, Spitzer RL, Williams JB. Structured Clinical Interview for DSM-IV Axis I Disorders: Patient Edition (SCID-I/P). New York: Biometrics Research, New York State Psychiatric Institute; 2002.

30. McGlashan TH, Miller TJ, Woods SW. Structured Interview for Prodromal Syndromes (SIPS), Version 4.0. New Heaven: Yale University; 2003.

31. Auther AM, Smith CW, Cornblatt BA. Global functioning: Social Scale (GF: Social). Glen Oaks, NY: Zucker-Hillside Hospital; 2006.

32. Niendam TA, Bearden CE, Johnson JK, Cannon TD. Global functioning: Role Scale (GF: Role). Los Angeles, CA: University of California, Los Angeles; 2006.

33. Andreasen NC. The Scale for the Assessment of Positive Symptoms (SAPS). Iowa City: University of Iowa; 1983.

34. Andreasen NC. The Scale for the Assessment of Negative Symptoms (SANS). Iowa City: University of Iowa; 1983.

35. Montgomery SA, Asberg M. A new depression scale designed to be sensitive to change. Br J Psychiatry 1979;134:382-389.

36. Mattila-Evenden M, Svanborg P, Gustavsson P, Åsberg M. Determinants of self-rating and expert rating concordance in psychiatric outpatients, using the affective subscales of the CPRS. Acta Psychiatr Scand 1996; 94:386-396.

37. Fusar-Poli P, Nelson B, Valmaggia L, Yung AR, McGuire PK. Comorbid depressive and anxiety disorders in 509 individuals with an at-risk mental state: impact on psychopathology and transition into psychosis. Schizophr Bull 2014; 40:120-131. 